\title{
Estimation and characterization of municipal solid waste generation in Thirukkovil Pradeshiya Sabha, Ampara District
}

\author{
Thivyatharsan R, Muhilini J \& Dasinaa S \\ Department of Agricultural Engineering, Faculty of Agriculture, Eastern University, Sri Lanka
}

\begin{abstract}
Municipal Solid Waste is a growing problem in urban areas of Sri Lanka and this problem is aggravated due to absence of proper solid waste management systems at Local Authorities. The management of solid waste requires in depth studies on waste generation and characterization. Thus, an evaluation study was conducted to assess the generation and composition of solid wastes in Thirukkovil Pradeshiya Sabha, Ampara district. Solid waste collected from households and shops by Local Authority were quantified. Then, collected samples were separated into different material categories of wastes. The questionnaire surveying covered 60 households in study area. Finally, data were analyzed using Microsoft Excel and SPSS.The results manifested that the average waste generation per household is 2.24 kilogram. Approximately, 16.345 tons of solid waste were found to be generated per day by household sector and has contributed more than $45.64 \%$ of the total waste generation. Correlation study revealed that the household waste generation showed a moderate positive correlation $(P<0.01)$ with monthly income and family size. The average composition of the household waste in weight basis is organic waste (92.94\%), plastic (3.96\%), metal (0.86\%), glass (1.67\%), and hazardous waste (0.57\%). Average solid waste generation per shop is 1.56 kilogram. Approximately 74.88 kilogram of solid waste were generated per day and the average composition of the shop waste is organic waste $(89.26 \%)$, plastic $(9.10 \%)$, glass $(0.94 \%)$, metal $(0.62 \%)$, and hazardous waste $(0.046 \%)$. The total solid waste collected by the Local Authority is 250.65 tons per week. The average composition of the solid waste collected by Local Authority was organic waste (93.69\%), plastic (2.73\%), glass $(1.03 \%)$, metal $(0.56 \%)$ and hazardous waste $(1.96 \%)$. The biodegradable material can be utilized for compost making to reduce the materials at home level.
\end{abstract}

KEYWORDS: Compost, dumping, hazardous waste, local authority, municipal solid waste

Corresponding author: S. Dasinaa, Email: dasin27@gmail.com 


\section{INTRODUCTION}

Waste products arise from our ways of life and they are generated at every stage of process of production and development all over the world where the generation of solid waste is an inevitable consequence of production and consumption activities in any economy (Eugenia et al., 2002). UNEP, (2005) also reported that fast expansion of urban, agricultural and industrial activities spurred by rapid population growth, has produced a huge amount of solid waste that pollutes the environment and destroys resources. Volume of waste generation and composition of MSW in a particular municipality or country depends on the economic status, population density, urban lifestyle, food habits, and geological condition (Duminda and Prasanna, 2005). Therefore, the generation of solid waste has become a critical global issue over the last decade due to escalating growth of population (Warith, 2003).

There are eight major categories of solid waste categorized as residential, industrial, commercial, institutional, construction and demolition, municipal services, process, and agricultural (WHO, 1984). It comprises countless different materials such as dust, food waste, packaging in the form of paper, metal, plastic or glass, discarded clothing, garden wastes, pathological waste, hazardous waste and radioactive waste etc. (WHO, 1984).

Solid waste management may be defined as the discipline associated with controlling the generation, storage, collection, transfer and transport, processing and disposal of solid waste in a manner that is in accordance with the best principles of health, economics, engineering, conservation, aesthetics, and other environmental consideration. However, waste management is a major challenge in urban areas throughout the world. Without an effective and efficient solid waste management program, the waste generated from various human activities, both industrial and domestic, can result in health hazards and have a negative impact on the environment (APO, 2007).

In Sri Lanka, proper establishment of solid waste management systems requires basic information on the nature of wastes, its composition, physical \& chemical characteristics and generated quantities. Composition of MSW provides a description of the constituents of the waste and it differs widely from place to place (Medina, 2002). This situation has exaggerated with dramatic changes in the solid waste stream due to domestic economic growth, urbanization and influence of global markets.

Also limitation of government funds to carry out extensive studies on solid waste system analysis has caused non-governmental organizations to engage in those activities but with narrow objectives. With those backgrounds, Thirukkovil Pradeshiya Sabha was selected as the study area which consists of different waste streams in its nature while comparing with other divisions located in the Ampara District. The composition of Municipal Solid Waste in that area also differs, from one stream to another. Since there is no reliable data on the quantum of solid waste generation and its composition, this study was mainly conducted to estimate the quantum of solid waste generation and its composition in the Thirukkovil Pradeshiya Sabha, Ampara District.

\subsection{Objectives of the study}

1. To estimate the quantum of solid waste generation in the Thirukkovil Pradeshiya Sabha, Ampara District.

2. To determine the composition of MSW of Thirukkovil Pradeshiya Sabha located in Ampara District.

\section{BACKGROUND OF THE STUDY}

Municipal Solid Waste (MSW) is the waste products generated from households, 
commercial establishments, institutions and business in municipal areas. Further, it generally consists of many different constituents, and these constituents are often porous and not fully saturated. Readily biodegradable (organic waste) are food waste, garden waste, animal waste and material contaminated by such waste.

Non putrescible are high resistant polymers are slowly biodegradable wastes (paper, wood, textiles, leather, plastic, rubber, paint, oil, grease, chemical, organic sludge) Non degradable (inorganic wastes) are glass, ceramic, mineral soil, rubble, tailing, slims, ash, concrete and construction debris etc. (Eusuf et al., 2007).

The term MSW is normally assumed to include all of the waste generated in a community, with the exception of waste generated by municipal services, treatment plants, and industrial and agricultural processes. Waste can be classified based on its source. The reason for using classification by source is that it is the specific composition of each waste category that sometimes recommends specific collection or treatment system for each one. This means that classification of waste will be determined by the socio economic sector generating the waste. (ISR and MEDCITIES, 2003).

The sources of solid waste have been classified as municipal (street sweeping, sewage treatment plant waste, waste from school and other institutions), domestic (garbage, rubbish, occasional large waste from homes), commercial (from stores and office), industrial (from manufacturing plant), mining (from coal mining, strip mining etc) and agricultural areas (Katyal and Satake, 1998).

Solid waste management chain requires intensive use of Environmental Sound Technology (EST) for its activities which could be as simple as containers for primary collection to as complicated as incinerators for disposal of hazardous waste (UNEP, 2009).To
Daskalopoulos et al., (1997), MSW management is said to be the discipline associated with the control of generation, storage, collection, transfer, processing and disposal of MSW, in a way which is governed by the best principles of public health, economics, engineering, aesthetics and other environmental considerations.

According to Collivignarelli et al., (2004), waste production and composition depend on many factors, such as the stage of development; socioeconomic, climatic and geographical conditions and collection frequency (Sharholy et al., 2008). With its resultant exponential growth coupled with insufficient data for planning, it does not enhance effective waste management besides, increasing population levels; rapid economic growth and rise in community living standards accelerate the generation rate of municipal solid waste in cities (Bartelings and Sterner, 1999).

Economic growth and waste generation have not been decoupled in both developing and industrialized world (Visvanathan and Trankler, 2006). Medina (2002) also reported that a positive correlation tends to exist between a community's income and the amount of solid waste generated. Wealthier individuals consume more than lower-income ones, which result in a higher waste generation rate for the former. Income and household size are the most significant factors affecting the quantity of solid wastes from household consumption.

Visvanathan and Trankler (2003) reported that in a family with a rich socioeconomic condition, daily waste generation rates are generally higher than the lower socioeconomic families. If the waste is more hazardous, it should be handled with the proper disposing techniques. This study was aimed to create the possibility to earn an income by selling recyclable wastes by adapting safety and environmentally friendly methods in those areas. 


\section{MATERIALS AND METHODS}

The study was conducted in the Thirukkovil Pradeshiya Sabha, Ampara District where the population density was 29,074 comprised of 18 G.N divisions (Divisional Secretariat, Thirukkovil) during the period of January to August, 2015.

Therefore, a questionnaire study was formulated to assess the generation and composition of wastes (nature of the waste, its composition, physical and chemical characteristics and quantities generated) to estimate the quantum of daily collected waste by the Local Authority (LA).

\subsection{Sampling method of field survey}

Thirukkovil Pradeshiya Sabha was divided into 10 sections based on the GN division. To ensure adequate representation, statistically $10 \%$ was allocated with 3 replicates from each sector. Questionnaire survey was carried out among sixty randomly selected households from the sampling point, twenty households were selected from each GN division (Thirukkovil, Thambiluvil, and Vinayagapuram) in order to get primary data about their income and other information required for this study such as number of household members, occupation, and methods of waste disposal.

Further, labeled bags were distributed among the selected sampling points and for the study purpose, the waste stream was divided into different sectors such as households, shops, etc. where the waste was collected from sampling points at one day interval for two weeks to analyze the composition.

Collected samples were weighed and recorded and finally, $25 \%$ of samples were separated and weighed to find out the composition of generated waste such as organic waste, plastic, metal, glass and hazardous waste. As a result, data was analyzed statistically using SPSS (statistical Package for Social Science, version16) to find the correlation between the amount of waste generated with the income level of family and the number of members in a family.

\section{RESULTS AND DISCUSSION}

The present investigation was undertaken with a view for assessing the solid waste generation and composition in the Thirukkovil Pradeshiya Sabha.

\subsection{Waste generation in households}

According to the figure 1, the average waste generation was higher in the Thambiluvil GN division $(2.75 \mathrm{~kg})$ due to the higher population density of the urban area. Visvanathan and Trankler, (2003) reported that the solid waste generation depends on the economy of the people.

Per capita waste generation increases with the income level of the family or individual. Hence, income level is also considered in this study to find out the relationship between income level and household waste generation.

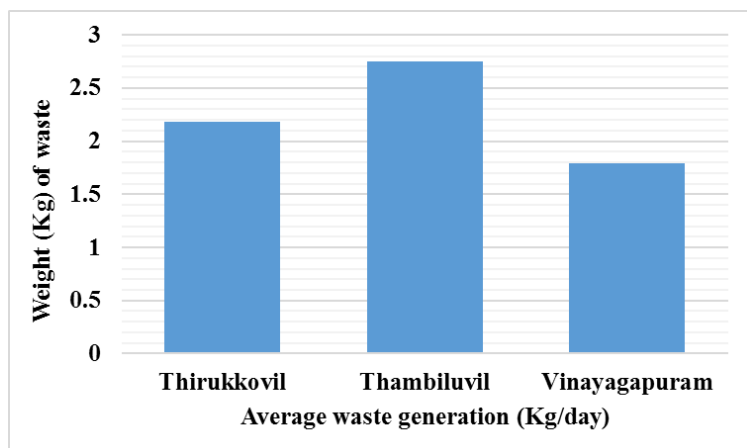

Figure 1: Average waste generation of household per day

Total household waste generation was significantly higher in Thambiluvil GN division $(7812.75 \mathrm{~kg})$ during the study period. As shown in figure 2, the value ranged between 3645.64 
$\mathrm{kg}$ and $7812.75 \mathrm{~kg}$ due to the living standards of the population in Ampara District.

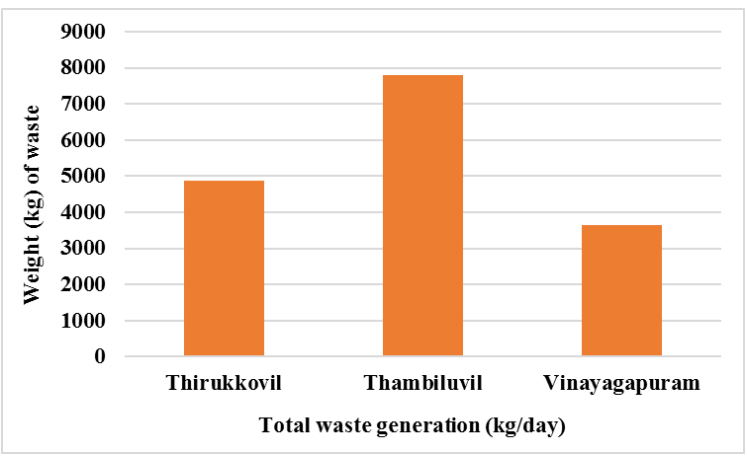

Figure 2: Total household waste generation in Thirukkovil Pradeshiya Sabha

\subsection{Relationship between solid waste generation and family size}

The Figure 3 shows the number of members of families in each GN division of the Thirukkovil Pradeshiya Sabha. Ghorbani et al., (2007) reported that family size is an important determinant in household waste production.

According to the findings, there was a significant positive correlation $(r=0.497$, $\mathrm{P}<0.01$ ) between waste generation and number of family members. Ghorbani et al., (2007) also reported that per capita waste production and total family waste production is increased by increasing family size. This finding also supports the results obtained in this study.

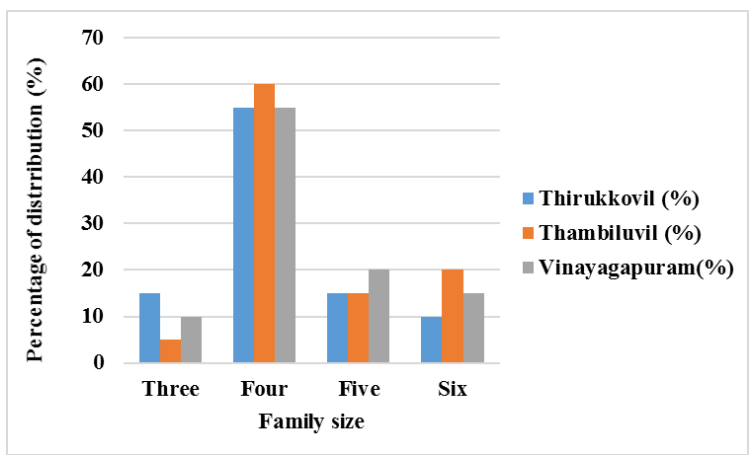

Figure 3: Number of family members in each GN division

\subsection{Relationship between income level and waste generation}

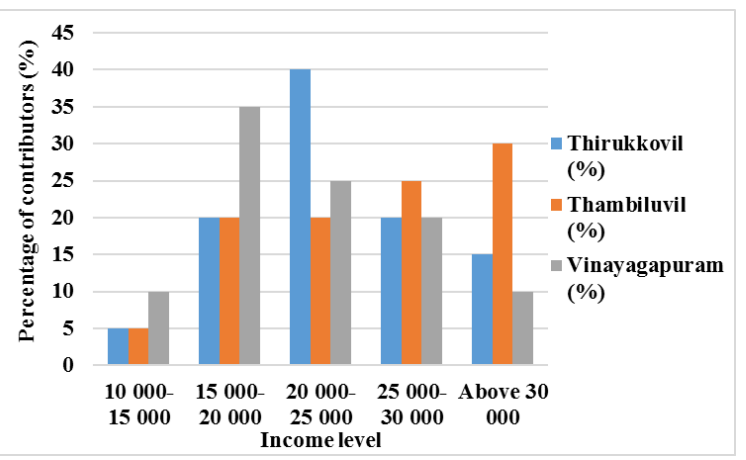

Figure 4: Income level of families

According to these results (Figure 3.4), higher percentage of families in Thambiluvil GN division came under the higher income level (Above 30,000) and higher percentage of families in Vinayagapuram GN division came under the low income level (10,000-15,000) than other GN division in Thirukkovil Pradeshiya Sabha. Correlation study revealed that the household waste generation was positively correlated with monthly income ( $\mathrm{r}=$ $0.519, \mathrm{p}>0.01)$ where the household waste generation increased with an increasing household income. Beukering and Sehker, (1999) also reported that a positive relationship exists between income levels and waste generation at the household level.

\subsection{Solid waste characterization}

\subsubsection{Household waste characterization}

In this analysis, there are five major categories of household solid waste identified such as organic waste, plastic, glass, metal, and hazardous waste. Benjamin and Mansoor, (2004) stated that Municipal Solid Waste (MSW) quantity and composition analysis is fundamental for the planning of municipal solid waste management services. Based on the figure 5 , the composition of the household waste measured (by weight) was as organic waste (93.9\%), plastic $(3.7 \%)$, metal $(0.7 \%)$, glass $(1.3 \%)$, and hazardous $(0.4 \%)$ in Thirukkovil 
GN division, organic waste $(90.2 \%)$, plastic (6.1\%), metal (1.1\%), glass (1.9\%), and hazardous $(0.7 \%)$ in Thambiluvil GN division and organic waste $(94.7 \%)$, plastic $(2.1 \%)$, metal $(0.8 \%)$, glass $(1.8 \%)$, and hazardous $(0.6 \%)$ in Vinayagapuram GN division.

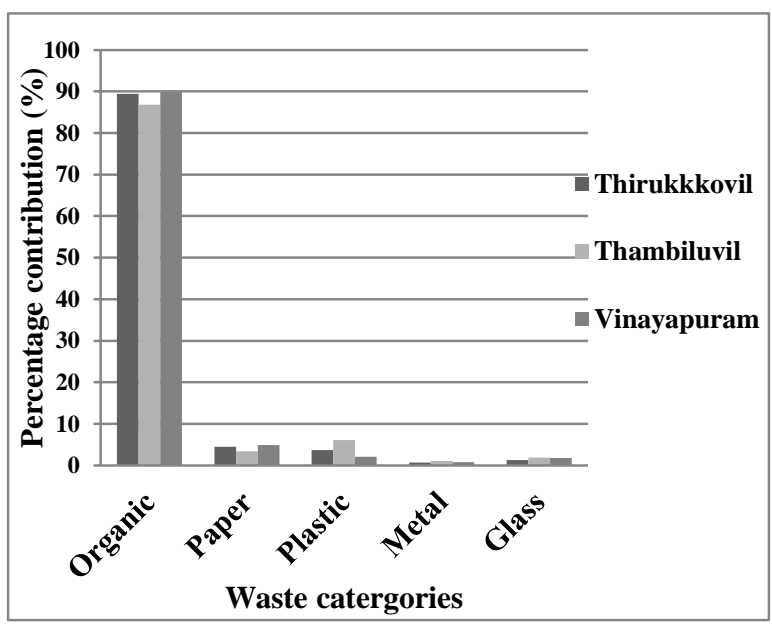

Figure 5: Household waste compositions in Thirukkovil Pradeshiya Sabha

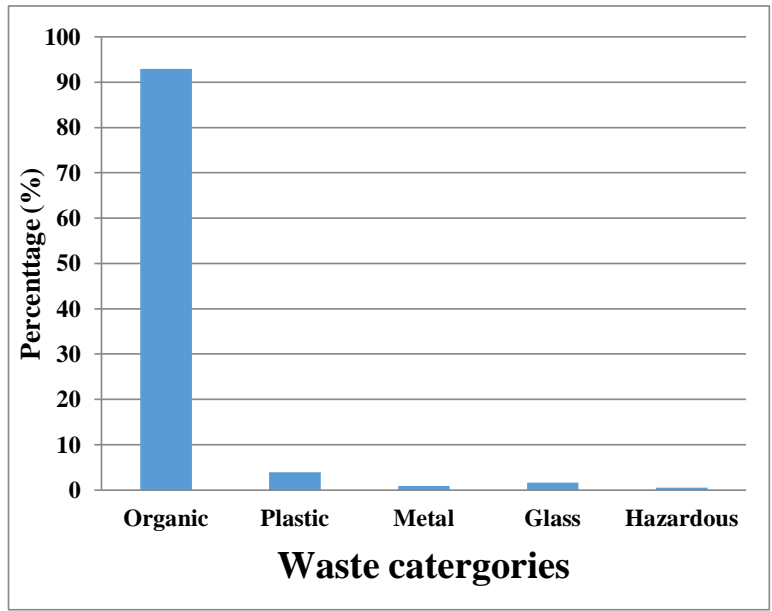

Figure 6: Average household waste compositions

Household waste composition study revealed that an approximately $92.94 \%$ of waste comes under the category of biodegradable and nearly $7.16 \%$ of waste comes under the category of non-bio degradable waste in Thirukkovil
Pradeshiya Sabha (figure 6). Hoornweg, (1999) reported that more than $80 \%$ of waste generated in household is biodegradable and in other words, it is capable of natural decomposition.

According to these results, there is a possibility to adopt environmentally acceptable waste management system like compost making at household level because of the higher production of biodegradable wastes. However, the awareness has to be created at household level for active participation in waste management system. Further, metal and glass made up small fraction of residential waste in study area. Local scavengers pick up scrap metal and glass on regular basis and return to recycling center. Income level, economic growth and lifestyle have strong influence on MSW composition (Zhu et al., 2008). Wealthier individuals consume more packaged products which result in higher percentage of inorganic materials such as metals, plastic, glass, textiles, and so on in the waste stream. Higher volumes of waste and a changing composition have a profound impact on waste management practices (Medina, 2002).

\subsubsection{Composition of shop's waste}

Details of composition of shop's wastes were given in Figure 7. Based on this finding, the organic waste, plastic and paper were most prominent wastes in shops.

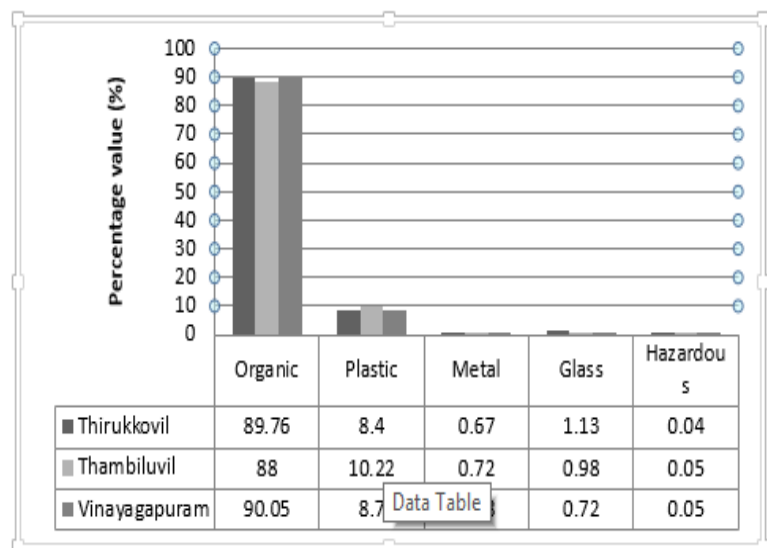

Figure 1: Shops waste composition 
The total number of shops in Thirukkovil Pradeshiya Sabha was 68 (Divisional Secretariat, Thirukkovil) which were differing from large scale to small scale based on their income. Therefore, its waste generation was also differing (large scale shops generated higher amount of waste than small scale) with the average waste generation (1.56 kilogram/shop/day) and total waste generation (106.08 kilo gram/day).

\subsubsection{Collected waste composition by local authority}

Local Authority collected waste from different waste streams such as shops, hospital, markets etc. However, there was no significant difference observed in organic waste percentage. Table 1 shows the average composition of waste collected by Local Authority in Thirukkovil Pradeshiya Sabha DS Division.

Table 1. Composition of waste collected by Local Authority

\begin{tabular}{|c|c|c|c|}
\hline Composition & Thirukkovil & Thambiluvil & Vinayapuram \\
\hline $\begin{array}{c}\text { Organic } \\
\text { waste }\end{array}$ & $94.5 \%$ & $91 \%$ & $95.6 \%$ \\
\hline Plastic & $2.8 \%$ & $4.5 \%$ & $0.9 \%$ \\
\hline Glass & $0.8 \%$ & $0.8 \%$ & $1.5 \%$ \\
\hline Metal & $0.4 \%$ & $0.9 \%$ & $0.4 \%$ \\
\hline Hazardous & $1.5 \%$ & $2.8 \%$ & $1.6 \%$ \\
\hline
\end{tabular}

\subsubsection{Average waste composition of collected waste by Local Authority}

According to the population data, the estimated household waste was 114.42 tons per week and waste collected by Local Authority was 250.65 tons per week. According to the results, it was clear that the household sector contributes $45.64 \%$ of the total solid waste generation and the estimated shops waste was 0.742 tons per week where shops sector contributed $0.29 \%$ of the solid waste in Thirukkovil Pradeshiya Sabha. However, this study was mainly focused on some major types of waste generated in household except leather, textile etc.

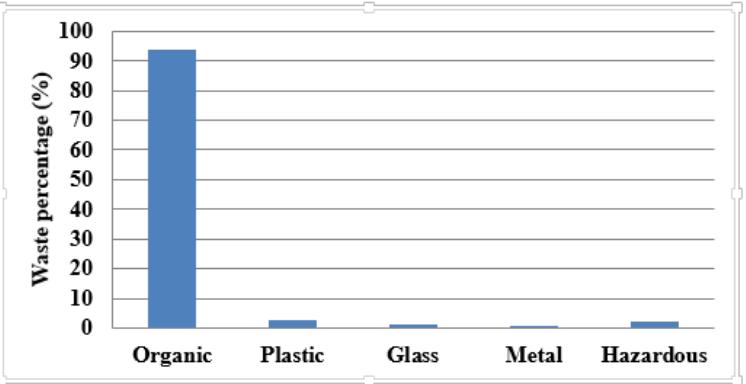

Figure 2: Average waste composition of collected waste by Local Authority

Plastic, glass, and metal percentage in the waste collected by Local Authority was lower than that in household. In many households, peoples reused plastic and glass waste such as cans, pipes, and bottles for some other purposes. Some people also sell bottles, papers, metal items to local scavengers or shops and earn income. This may be the reason for lower percentage of plastic, glass, and metal in collected waste.

Pilapitiya, (2006) reported that a bottle and paper collector in Colombo, collecting newspaper and glass from householders and paying such amount to the household members. And also, an average scrap metal collector can earn between Rs.400 to 700 per day in Colombo (Fernando, 2006). In addition, composition of collected waste loads by Local Authority had slightly higher percentage of hazardous waste than the waste collected directly from household.

\subsection{Existing and possible waste disposal/ Treatment methods in the study area}

According to the questionnaire survey, there are several methods of waste disposal/treatment adopted such as the burning, municipal collection, family pit disposal, and making organic fertilizer or combinations above by the residents in Thirukkovil Pradeshiya Sabha. The following figure 9 indicates the percentage of waste disposal/treatment methods adopted by people in study area. 


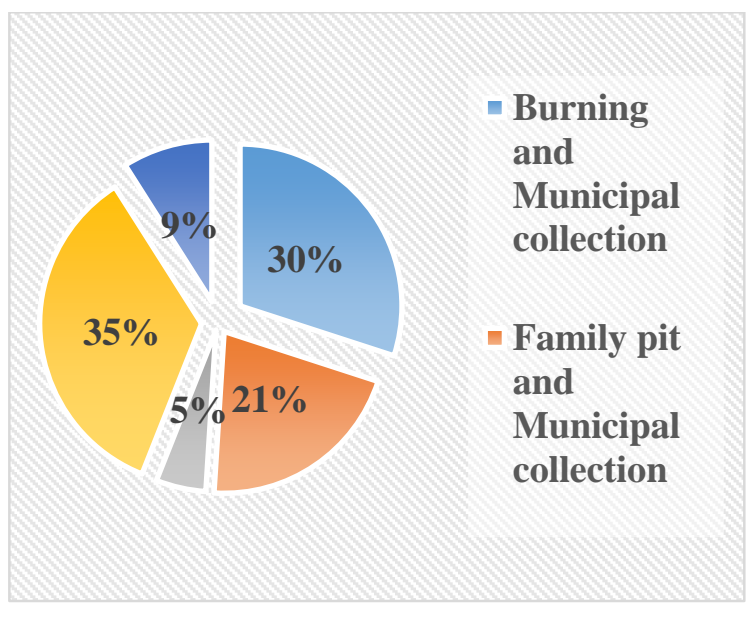

Figure 3: Different waste disposal methods in study area

Burning, municipal collection and family pit disposal are major disposal methods/treatment used in this area. The uncontrolled dumping of such wastes have not only brought about increasing number of incidents of health hazards but also causing the ground water contamination and thus posing serious threat to the human being (Medina, 2002).

Here, only small percentage of people (9\%) is producing organic fertilizer/compost as a waste utilization technique. Composting is a form of recycling which can play a key role in diverting organic waste from unusable disposal. Composting reduces the cost of waste disposal, increase the recovery rate of recyclable materials, improve soil fertility, and produce a clean and readily marketable finished product. It is also an environmental friendly or safe method of disposal. Composting is beneficial in a solid waste management system because it reduce organic waste to 25-30 percent of its initial weight. It need to be enhanced through such awareness among the society regarding compost making and other safeguard reuse, recycling and reduce pattern.

\section{CONCLUSIONS}

The findings showed that, approximately 16.345 tons of solid waste generated per day by household sector and household sector contributes more than $45.64 \%$ of total waste generation from other sources. In addition, correlation study revealed that there was a significant positive correlation $(\mathrm{P}<0.01)$ between household waste generation and monthly income and family size. Further, approximately $92.94 \%$ of waste was classified as biodegradable and nearly $7.06 \%$ of waste was considered as non-biodegradable wastes. The total waste collected by Local Authority 250.65 tons per week which included approximately $93.69 \%$ waste as biodegradable and nearly $6.31 \%$ of waste as nonbiodegradable. Even though, there were so many safe disposal methods available, burning, municipal collection and home pit disposal were the major disposal methods/treatment used in this area and only small percentage of people (9\%) contributed in producing organic fertilizer/compost as a waste utilizing technique.

\section{REFERENCE}

Asian Productivity Organization. Solid Waste Management: Issues and Challenges in Asia. Asian Productivity Organization, Tokyo, Japan. 2007; 3-270.

BARTELINGS H, STERNER T. Household Waste Management in a Swedish Municipality: Determinants of Waste Disposal, Recycling and Composting. Environment and Resource Economics. 1999; 13(4): 473- 491.

BEUKERING PV, SEHKER M. Analyzing Urban Solid Waste in Developing Countries. A Perspective in Bangalore. Working Paper No 24. India. 1999; 46-67.

COLLIVIGNARELLI C, SORLINI S, VACCARI, M. Solid Wastes Management in Developing Countries, CD-ROM of ISWA. World Congress. Rome; Italy. 2004.

DASKALOPOULOS E, BADR O, PROPERT S.D. Municipal Solid Waste: A Prediction 
Methodology for the Generation Rate and Composition in the European Union Countries and United States of America, Resources Conservation and Recycling'. 1998; 4(2):155166.

DUMINDA K, PRASANNA K. The Problem of Solid Waste: A case study of the Maharagama Local Authority, Journal of national Science Foundation. 2005: 33.

EUGENIA CB, GEORGINA N, RAMIL L. SOLID Waste Segregation and Recycling in Metro Manila: Household Attitudes and Behaviors. Resources, Environment and Economics Center for Studies. Philippines. 2002; 45-67.

EUSUF M, CHE MUSA CHE OMAR AND IBRAHIM M. An overview on waste generationCharacteristics in some selected local Authorities in Malaysia,International Islamic University Malaysia. 2007.

FERNANDO L. Solid Waste Segregation, Collection and Management in Colombo. Central Environmental Authority, Sri Lanka. 2006; 23-25.

GHORBANI M, LIAGHATI H, MAHMOUDI H. Household Waste Management in Mashad: Characteristics and Factors Influencing on Demand for Collecting Services. Pakistan Journal of Biological Science. 2007; 10(21): 3952-3955.

HOORNWEG D, THOMAS L, OTTEN L. Composting and Its Applicability in Developing Countries. Urban Waste Management Working Paper Series 8.Urban Development Division World Bank. Washington; USA. 1999; 2-I2

ISR, MEDICITIES. Guidelines for Municipal Solid Waste Management in the Mediterranean Region. Spain. 2003.5-23.
KATYAL T, SATAKE M. Environmental Pollution. Anmol PubliCations, Private Ltd. New Delhi; India.1998.65-126.

MEDINA M. Globalization, Development and Municipal Solid Waste Management in Third World Cities. Institute of Advance Studies. Mexico. 2002.

SHARHOLY M, AHMAD K, MAHMOOD G, TRIVEDI RC. Municipal Solid Waste Management in Indian Cities - A Review.Waste Management. 2008; 28 (2):459- 467.

United Nations Environment Programme. Selection, Design and Implementation of Economic Instruments in the Solid Waste Management Sector in Kenya. United Nations Environment Programme. Kenya. 2005; 157163.

United Nations Environment Programme. Developing Integrated Solid Waste Management Plan Training Manual: Assessment of Current Waste Management System and Gaps therein, 2009; 2.

VISVANATHAN C, TRANKLER J. Municipal Solid Waste Management in Asia: A Comparative Analysis. Workshop on Sustainable Landfill Management. 3-5 December. Chennai. India. 2003; 3-15.

WARITH MA. Solid waste management: New trends in landfill design. Emirates Journal for Engineering Research. 2003; 8 (1): 61-7.

World Health Organization. Solid Waste Management in South East Asia. WHO House, New Delhi, India. 1984.

ZHU D, ASNANI PU, ZURBRUGG C, ANAPOLSKY S, MANI S. Improving Municipal Solid Waste Management in India. World Bank; Washington: USA. 2008; I-8. 